\title{
Effect of Solvents on the Antioxidant Activity of Walnut (Juglans regia L.) Shell Extracts
}

\author{
Jiong Yang ${ }^{1}$, Chaoyin Chen ${ }^{1, *}$, Shenglan Zhao ${ }^{2}$, Feng Ge ${ }^{1}$, Diqiu Liu ${ }^{1}$ \\ ${ }^{1}$ Faculty of life science, Kunming University of Science and Technology, Kunming, People's Republic of China \\ ${ }^{2}$ Yunnan University of Traditional Chinese Medicine, Kunming, People's Republic of China \\ *Corresponding author: chaoyinchen@163.com
}

Received August 16, 2014; Revised August 27, 2014; Accepted September 09, 2014

\begin{abstract}
Walnut shell is a waste generated in the walnut (Juglans regia L.) harvest, containing natural compounds with antioxidant properties. In this connection, the effect of the solvent (water, chloroform, methanol, ethanol, ethyl acetate and N-butanol) on the extraction yields, total flavonoids content and antioxidant properties was analyzed. Total flavonoids content of extracts was determined by NaNO2-Al(NO3)3 method. Extract antioxidant activity was measured by hydroxyl, 2,2-diphenyl-1-picrylhydrazyl (DPPH) and superoxide anion radical scavenging capacity and the total antioxidant capacity and reducing power assay. The highest extraction yield was achieved with N-butanol (4.54\%) and the greatest total flavonoids content shown by the samples extracted with ethyl acetate. The highest ability to scavenging DPPH, hydroxyl and superoxide radicals was ethyl acetate extract (EC50=81.03 $\mu \mathrm{g} / \mathrm{mL}$ ), methanol extract $(E C 50=131.35 \mu \mathrm{g} / \mathrm{mL})$ and chloroform extract $(E C 50=176.35 \mu \mathrm{g} / \mathrm{mL})$ respectively under the concentration of $500 \mu \mathrm{g} / \mathrm{mL}$. The methanol extract showed the greatest total antioxidant activity and reducing power. The results showed that different solvent had significant effect on total flavonoids content and antioxidant activity. The result obtained demonstrated the potential of walnut shell as a source of antioxidant.
\end{abstract}

Keywords: walnut shell, solvent extraction, total flavonoids content, antioxidant activity

Cite This Article: Jiong Yang, Chaoyin Chen, Shenglan Zhao, Feng Ge, and Diqiu Liu, "Effect of Solvents on the Antioxidant Activity of Walnut (Juglans regia L.) Shell Extracts." Journal of Food and Nutrition Research, vol. 2, no. 9 (2014): 621-626. doi: 10.12691/jfnr-2-9-15.

\section{Introduction}

The walnut (Juglans regia L.) shell is a hard, nontoxic and biodegradable material which can be can be used as abrasive to polish gun casings, jewelry and metal material. And it is a good media to separate crude oil from water [1]. The shell can be used as a carbonaceous sorbent to control of mercury from industrial liquid streams [2]. The walnut shell has antioxidant compounds such as flavonoids which have been determined [3].

Solvent extraction is frequently used to isolate plant antioxidant compounds. However, the extract yields and antioxidant activities of the extracts are significantly different, mainly due to the chemical characteristics of extracts and the solubility of extract in a particular solvent [4]. Methanol [5], ethanol [6], chloroform [7], water [8], N-butanol [9] and ethyl acetate [10] are frequently employed for recovery of antioxidant compounds from a plant matrix.

Many synthetic antioxidants have been used to scavenge free radicals, while which has been suspected to threaten health by causing liver damage and carcinogenesis. Additional it will take a long time for them to complete their natural cycles, thus causing environmental pollution [11]. So researches need find natural antioxidants substitutes for the synthetic ones. As natural compounds, the flavonoids have a lot of biological characteristics such as antioxidant, antibacterial, antiinflammatory and anticancer $[12,13,14,15]$. In this context, the flavonoids, as natural antioxidants, attract more and more people's attention.

Moreover few researches have been reported about the antioxidant activity of walnut shell extractive. Then, the aim of this work was to analyse the antioxidant properties of extracts with different solvents from walnut shell. Solvents (water, chloroform, methanol, ethanol, ethyl acetate and N-butanol) of different polarity were used. Then, the extracts were studied, regarding their total flavonoids content and antioxidant activities. Antioxidant potential was accessed by the scavenging effect on DPPH, superoxide anion and hydroxyl free radicals, the reducing power and total antioxidant capacity assay.

\section{Materials and Methods}

\subsection{Chemicals}

Chloroform, methanol, ethyl acetate, N-butanol and ethanol were obtained from Chongqing Chuandong Chemical group Co., Ltd. (Chongqing China). Rutin, $\mathrm{DPPH}$, 1,10-phenanthroline and pyrogallol were purchased from Sigma-Aldrich (China). Iron chloride $\left(\mathrm{FeCl}_{3}\right)$, sodium nitrite $\left(\mathrm{NaNO}_{2}\right)$, aluminum nitrate 
[Al $\left.\left(\mathrm{NO}_{3}\right)_{3}\right]$, sodium dihydrogen phosphate dihydrate, potassium hexacyanoferrate $\left[\mathrm{K}_{3} \mathrm{Fe}(\mathrm{CN})_{6}\right]$, trichloroacetic acid, disodium hydrogen phosphate, hydrogen peroxide $\left(\mathrm{H}_{2} \mathrm{O}_{2}\right)$, ammonium molybdate, sulfuric acid $\left(\mathrm{H}_{2} \mathrm{SO}_{4}\right)$, ferrous sulfate $\left(\mathrm{FeSO}_{4}\right)$, 2-Amino-2-(hydroxymethyl)-1,3propanediol (TRIS), hydrochloric acid ( $\mathrm{HCl}$ ) and trisodium phosphate $\left(\mathrm{Na}_{3} \mathrm{PO}_{4}\right)$ were from Tianjin Fengchuan Chemical Reagent Science And Technology Co., Ltd. (Tianjin China).

\subsection{Raw Material}

The sampling of raw material was following the method described by Fernández-Agulló [7] with some modifications. Sample of walnut shells were collected in Zhaotong city in Yunnan province of China. Prior to the use, the walnut shells cleaned of dirt and impurities firstly, and then were ground into flour using a grinder. To preserve antioxidant properties, the particles were stored in plastic bags, immediately frozen at $-70^{\circ} \mathrm{C}$ for further use.

\subsection{Extracts Preparation}

The extracts were following the method described by Fernández-Agulló [7] with a little modification. In the extractions with water, $12 \mathrm{~g}$ of powdered sample were extracted with $200 \mathrm{~mL}$ of boiling water for 1 hour and filtrated through Whatman no. 4 paper. For the chloroform, methanol, ethyl acetate, N-butanol and ethanol extraction, $12 \mathrm{~g}$ of sample were extracted with $200 \mathrm{~mL}$ of the tested solvent for 1 hour at $50^{\circ} \mathrm{C}$ in a water bath and filtered through Whatman no. 4 paper. The filtrates were frozen, lyophilized and the each extract redissolved in water at concentrations of $10 \mathrm{mg} / \mathrm{mL}$ for antioxidant assays. All the extractions were done in triplicate [7].

\subsection{Total Flavonoids Content}

The total flavonoids content (TFC) in the obtained extracts was determined using the $\mathrm{NaNO}_{2}-\mathrm{Al}\left(\mathrm{NO}_{3}\right)_{3}$ method described by $\mathrm{Li}$ [16] with a slight modifications. Briefly $1 \mathrm{~mL}$ sample was mixed with $0.3 \mathrm{~mL} \mathrm{NaNO}_{2}$ aqueous solution $(5 \%, \mathrm{w} / \mathrm{w})$. The mixture was deposed for $6 \mathrm{~min}$, followed by the addition of $0.3 \mathrm{~mL} \mathrm{Al}\left(\mathrm{NO}_{3}\right)_{3}$ aqueous solution $(10 \%$, w/w). After $6 \mathrm{~min}, 4 \mathrm{~mL} \mathrm{NaOH}$ aqueous solution $(4 \%$, w/w) was added and the volume was made up to $10 \mathrm{~mL}$ with distilled water. The solution was mixed and absorbance was measured against the blank at $510 \mathrm{~nm}$. The determinations were performed in triplicate, and the results were based on the calibration curve obtain with rutin. The TFC was calculated as a rutin equivalent and expressed as g rutin equivalents (REs)/g of extract.

\subsection{Antioxidant Activity}

\subsubsection{DPPH Scavenging Activity}

The DPPH free radical scavenging ability of the extracts was following the method described by Islam [17] with some modifications. The $2.0 \mathrm{~mL}$ of aqueous solutions of sample extracts $(100-500 \mu \mathrm{g} / \mathrm{mL})$ were mixed with $2.0 \mathrm{~mL}$ DPPH solutions $\left(4 \times 10^{-4} \mathrm{M}\right.$ in ethanol). The mixture was shaken forcibly and left to stand in the dark. After 30 minutes of reaction period at room temperature, the absorbance was measured at $517 \mathrm{~nm}$. The scavenging effect was calculated using the following formula: scavenging effect $(\%)=\left[1-\left(A_{i}-A_{j}\right) / A_{0}\right] \times 100$, where $A_{i}$ is the absorbance of the DPPH solutions containing samples, $A_{j}$ is the absorbance of the antioxidant in ethanol and $A_{0}$ is the absorbance of the DPPH solution. The effective concentration which scavenges $50 \%$ radical $\left(\mathrm{EC}_{50}\right)$ was concluded from the graph of scavenging effect percentage against the samples concentration.

\subsubsection{Hydroxyl Free Radical Scavenging Capability}

The hydroxyl free radical scavenging capability was according to the method described by Chen [18], with a little modification. A reaction mixture containing $1 \mathrm{~mL}$ of 1,10-phenanthroline $(0.75 \mathrm{mM}), 1.5 \mathrm{~mL}$ of $0.75 \mathrm{mM}$ $\mathrm{FeSO}_{4}$ and $3.8 \mathrm{~mL}$ of $0.2 \mathrm{M}$ phosphate buffer solution $(\mathrm{pH}$ 7.4) was mixed with $1 \mathrm{~mL}$ of sample extracts (100-500 $\mu \mathrm{g} / \mathrm{mL})$ and $1.0 \mathrm{~mL}$ of $0.01 \%(\mathrm{v} / \mathrm{v}) \mathrm{H}_{2} \mathrm{O}_{2}$ the volume was made up to $10 \mathrm{~mL}$ with distilled water. The mixture was incubated at $37^{\circ} \mathrm{C}$ for $60 \mathrm{~min}$, and the absorbance was measured at $536 \mathrm{~nm}$. The scavenging effect was calculated using the following equation: scavenging effect (\%) = $\left[\left(A_{2}-A_{1}\right) /\left(A_{0}-A_{1}\right)\right] \times 100$. Where $A_{2}$ and $A_{1}$ are the absorbance with or without of sample, and $A_{0}$ is the absorbance without sample and $\mathrm{H}_{2} \mathrm{O}_{2}$. The effective concentration which scavenges $50 \%$ radical $\left(\mathrm{EC}_{50}\right)$ was concluded from the graph of scavenging effect percentage against the samples concentration.

\subsubsection{Superoxide Anion Radical Scavenging Ability}

The superoxide anion scavenging activity of the extracts was according to the method described by $\mathrm{Hu}$ [19] with some modifications. Briefly, $5 \mathrm{~mL}$ Tris- $\mathrm{HCl}$ buffer (0.05M, pH 8.2) and $4 \mathrm{~mL}$ of samples $(100-500 \mu \mathrm{g} / \mathrm{mL})$ were left at $25^{\circ} \mathrm{C}$ for 20 minutes, after which $1 \mathrm{~mL}$ of pyrogallol at same temperature were added to the blend, and the mixture were incubated at $25^{\circ} \mathrm{C}$ for 5 minutes. Then, the reaction system was ended by addition $1 \mathrm{~mL}$ of $\mathrm{HCl}(10 \mathrm{M})$. The absorbance of the mixture was measured by a spectrophotometrically at $320 \mathrm{~nm}$. The scavenging effect was calculated using the following equation: scavenging effect $(\%)=\left(1-A_{1} / A_{0}\right) \times 100$, where $A_{1}$ and $A_{0}$ are the absorbance of the reaction system with or without the test samples. The effective concentration which scavenges $50 \%$ radical $\left(\mathrm{EC}_{50}\right)$ was concluded from the graph of scavenging effect percentage against the samples concentration.

\subsubsection{Total Antioxidant Capacity}

The total antioxidant capacity of the samples was following the ammonium molybdate reduction method described by [20]. For this assay $1 \mathrm{~mL}$ of the test samples $(100-500 \mu \mathrm{g} / \mathrm{mL})$ were mixed with $1 \mathrm{~mL}$ of the reagent solution ( $4 \mathrm{mM}$ ammonium molybdate, $0.6 \mathrm{M} \mathrm{H}_{2} \mathrm{SO}_{4}$ and $\left.28 \mathrm{Mm} \mathrm{Na}_{3} \mathrm{PO}_{4}\right)$. The tubes were incubated in a water bath at $90^{\circ} \mathrm{C}$ for $90 \mathrm{~min}$. After cooling to room temperature, the absorbance of the reaction mixture was measured at 695 $\mathrm{nm}$ with higher absorbance values indicative of greater reducing power.

\subsubsection{Reducing Power Assay}

The reducing power was determined according to the method described by Lue [21] with some modifications. 
Different concentrations (100-500 $\mu \mathrm{g} / \mathrm{mL})$ of sample (1 $\mathrm{mL}$ ) were mixed with phosphate buffer $(2.5 \mathrm{~mL}, 0.2 \mathrm{M}$, $\mathrm{pH}$ 6.6) and $2.5 \mathrm{~mL}$ of $1 \% \mathrm{~K}_{3} \mathrm{Fe}(\mathrm{CN})_{6}$. The mixture was incubated at $50^{\circ} \mathrm{C}$ for $20 \mathrm{~min}$, after which trichloroacetic acid $(2.5 \mathrm{~mL}, 10 \%, \mathrm{~m} / \mathrm{v})$ was added to terminate the reaction. Then the mixture was centrifuged at $3000 \mathrm{~g}$ for $10 \mathrm{~min}$. $2.5 \mathrm{~mL}$ of the upper layer was mixed with $2.5 \mathrm{~mL}$ of distilled water and $0.5 \mathrm{~mL}$ of $\mathrm{FeCl}_{3}(1 \%, \mathrm{~m} / \mathrm{v})$. The absorbance was measured by a spectrophotometrically at $700 \mathrm{~nm}$, with higher absorbance values indicative of greater reducing power.

\subsection{Statistical Analysis}

All the experiments were carried out in triplicate. The results are expressed as mean values and standard error of the mean. The existence of significant differences among the results for extraction yield, total flavonoids content and the antioxidant properties of the extracts was analysed. The one-way analysis of variance (ANOVA) and Duncan's test were used. All statistical tests were used SPSS 19.0 software at a 5\% significance level. The EC $_{50}$ values obtained in the antioxidant assays was established regression equation between the samples concentration and the scavenging effect.

\section{Results and Discussion}

Water, chloroform, methanol, ethanol, ethyl acetate and N-butanol are common solvents with different polarity. Extraction with different polarity solvents has been frequently used for the isolation of antioxidant compounds $[22,23,24]$, both the extraction yield and antioxidant activity of the extracts have a strong relationship with solvent employed, mainly due to the different polarity of the extracts and the solubility of extracts in solvents [7]. Besides, the extracts with different solvents maybe contain different ingredients. For this reason, those solvents were assayed for the extraction of walnut shell in this work. The extraction yield, total flavonoids content and antioxidant properties of the extracts obtained were compared.

\subsection{The Extraction Yield and Total Flavonoids Content}

The extraction yield of various solvent showed significantly different $(\mathrm{P}<0.05)$. The values of extraction yield varied from $0.42 \%$ for the chloroform extract to $4.54 \%$ for the N-butanol extract. The extraction yield increased in the following order: chloroform < ethyl acetate $<$ ethanol $<$ water $<$ methanol $<$ N-butanol. Few researches have been reported about the extraction yield of walnut shell extracts. The results were similar with Sahreen's, the ME had a higher extraction yield and total flavonoids content [25]. The total flavonoids content of extracts with different solvents from walnut shell was different $(\mathrm{P}<0.05)$. The ethyl acetate extract $(162.54 \mathrm{mg}$ $\mathrm{REs} / \mathrm{g}$ extract) showed the highest amount of these compounds. This result was higher than those results obtained by Akbari [3] but lower than the results got by Chaleshtori [26]. Table 1 showed the results obtained for extraction yield and total flavonoids content.

Table 1. Extraction yield (in percentage) and total flavonoids content (mg REs/g extract) of walnut shell from Zhaotong city in Yunnan province of China

\begin{tabular}{ccc} 
province of China & Extraction yield (\%) & Total flavonoids content (mg REs/g extract) \\
\hline Solvent & $2.62 \pm 0.08 \mathrm{c}$ & $9.61 \pm 0.51 \mathrm{a}$ \\
Water & $3.20 \pm 0.08 \mathrm{~d}$ & $98.85 \pm 3.76 \mathrm{e}$ \\
Methanol & $1.86 \pm 0.13 \mathrm{~b}$ & $18.97 \pm 0.21 \mathrm{~b}$ \\
Ethanol & $0.42 \pm 0.01 \mathrm{a}$ & $30.10 \pm 1.92 \mathrm{c}$ \\
Chloroform & $4.54 \pm 0.20 \mathrm{e}$ & $62.10 \pm 2.04 \mathrm{~d}$ \\
N-butanol & $1.85 \pm 0.07 \mathrm{~b}$ & $162.54 \pm 1.61 \mathrm{f}$ \\
Ethyl acetate
\end{tabular}

Data are means of three replicates with standard errors. Values in the same column followed by a different letter are significantly different (p<0.05).

\subsection{Antioxidant Activity}

In biological systems, the imbalance between the oxidants (free radicals, reactive oxygen species) and antioxidants leads to lipids, proteins and DNA damage. Over-production of oxidants or over-decrease in antioxidants may contribute to development of many hearth diseases [27]. Antioxidant activity of the antioxidants is concerning with those compounds capable of protecting the organism system against the potential harmful effect of oxidative stress [7]. Several studies were developed concerning the antioxidant activity of extracts from walnut shell. In this study, the antioxidant capacity of extracts from walnut shell was accessed by five different assays: scavenging activity on DPPH radicals, hydroxyl free radical and superoxide anion radical, reducing power and total antioxidant capacity. The $\mathrm{EC}_{50}$ values of different solvents extracts of walnut shell were shown in Table 2. The low $\mathrm{EC}_{50}$ value represented high antioxidant capability.

Table 2. $\mathrm{EC}_{50}$ values of different solvents extracts of walnut shell from Zhaotong city in Yunnan province of China

\begin{tabular}{|c|c|c|c|}
\hline \multirow{2}{*}{ Solvent } & \multicolumn{3}{|c|}{$\mathrm{EC}_{50}(\mu \mathrm{g} / \mathrm{mL})$} \\
\hline & DPPH & Hydroxyl free radical & Superoxide radical \\
\hline Water & $220.05 \pm 2.10 \mathrm{~d}$ & $304.47 \pm 2.98 \mathrm{e}$ & $173.41 \pm 3.56 \mathrm{a}$ \\
\hline Methanol & $151.42 \pm 5.08 c$ & $131.35 \pm 3.20 \mathrm{~b}$ & $451.28 \pm 3.04 \mathrm{e}$ \\
\hline Ethanol & $263.06 \pm 11.17 f$ & $211.91 \pm 3.99 c$ & $419.09 \pm 4.13 \mathrm{~d}$ \\
\hline Chloroform & $239.06 \pm 4.12 \mathrm{e}$ & $270.65 \pm 7.86 \mathrm{~d}$ & $176.35 \pm 3.07 b$ \\
\hline N-butanol & $109.74 \pm 2.31 b$ & $392.46 \pm 1.77 \mathrm{f}$ & $413.42 \pm 3.64 d$ \\
\hline Ethyl acetate & $81.03 \pm 2.31 \mathrm{a}$ & $97.32 \pm 3.29 a$ & $229.45 \pm 6.39 c$ \\
\hline
\end{tabular}

Data are means of three replicates with standard errors. Values in the same column followed by a different letter are significantly different (p<0.05).

\subsubsection{DPPH Free Radical Scavenging Capability}

$\mathrm{DPPH}$ is a stable organic nitrogen free radical. The $\mathrm{DPPH}$ scavenging capability has been widely used to evaluate the antioxidant capacity of extracts from different plant materials. DPPH is scavenged by reductants contained in the tested materials through the donation of hydrogen, forming its reduced form. The color changes 
from purple to yellow after reduced, which can be quantified by its decrease of absorbance at the wavelength of $517 \mathrm{~nm}$ [28]. Figure 1 show that the DPPH radical scavenging ability of the extracts. The DPPH free radical scavenging capabilities of water extract (WE), methanol extract (ME), ethyl acetate extract (EAE), N-butanol extract (NBE), ethanol extract (EE) and chloroform extract (CE) were 80.75\%, 72.74\%, 87.32\%, 84.85\%, $72.50 \%$ and $60.12 \%$, respectively under the concentration of $500 \mu \mathrm{g} / \mathrm{mL}$, and in the order of EAE $>\mathrm{NBE}>\mathrm{WE}>$ $\mathrm{ME}>\mathrm{EE}>\mathrm{CE}$. The $\mathrm{DPPH}$ radicals scavenging capabilities of extracts except CE were stronger than the result obtained by Fernández-Agulló [7] and Chen [18]. The scavenging capabilities of each extract exhibited concentration dependant effects, the higher the concentration of the extract with the stronger scavenging activity.

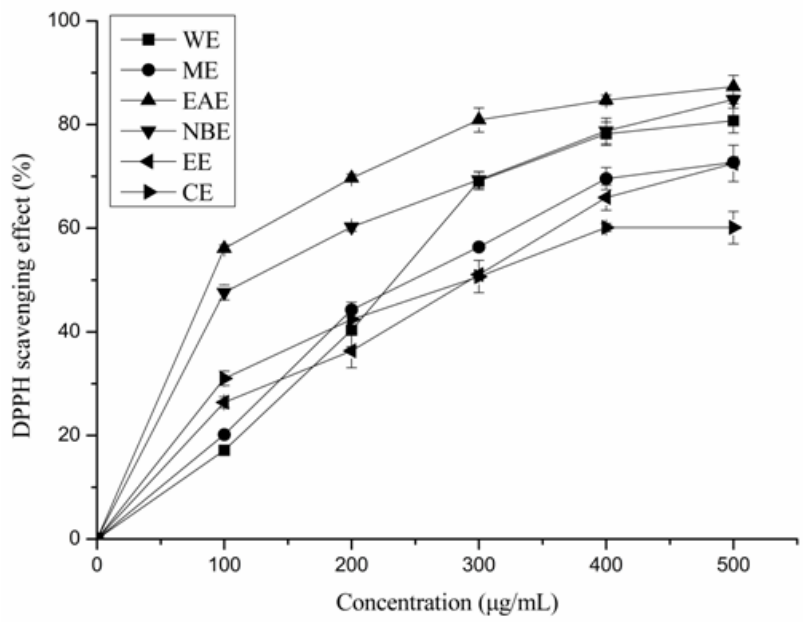

Figure 1. Scavenging activity on DPPH radicals (\%) of the extracts obtained with water extract (WE), methanol extract (ME), ethanol extract (EE), chloroform extract (CE), N-butanol extract (NBE) and ethyl acetate extract (EAE)

\subsubsection{Hydroxyl Free Radicals Scavenging Activity}

Hydroxyl free radical can be formed from superoxide anion and hydrogen peroxide is the most reactive free radical in the presence of metal-ions [18]. When a hydroxyl radical reacts with aromatic compounds, it can add on across a double bond, creating new radical. The resulting radical can undergo further reactions, such as generating peroxyl radical, or decompose to phenoxyl type radicals by water elimination [29,30]. Hydroxyl radicals can react with lipid, polypeptides, proteins and DNA, especially thiamine and guanosine. In organism those radicals can cause damage to biological macromolecules. The $\mathrm{EC}_{50}$ value of WE, ME, EAE, NBE, EE and CE are 304.47, 131.5, 97.32, 392.46, 211.91 and $270.65 \mu \mathrm{g} / \mathrm{mL}$. As show in Figure 2, the hydroxyl free radical scavenging rates are $85.11 \%, 93.20 \%, 82.97 \%, 62.15 \%$, 51.43\%, and $87.05 \%$, respectively when the concentrations of extracts of WE, ME, EAE, NBE, EE and CE were $500 \mu \mathrm{g} / \mathrm{mL}$. These results were much higher than those results obtained by Chen [18] but couldn't compare with Loganayaki's results [31]. The scavenging capabilities of each extract exhibited concentration dependant effects, the higher the concentration of the extract with the stronger scavenging activity.

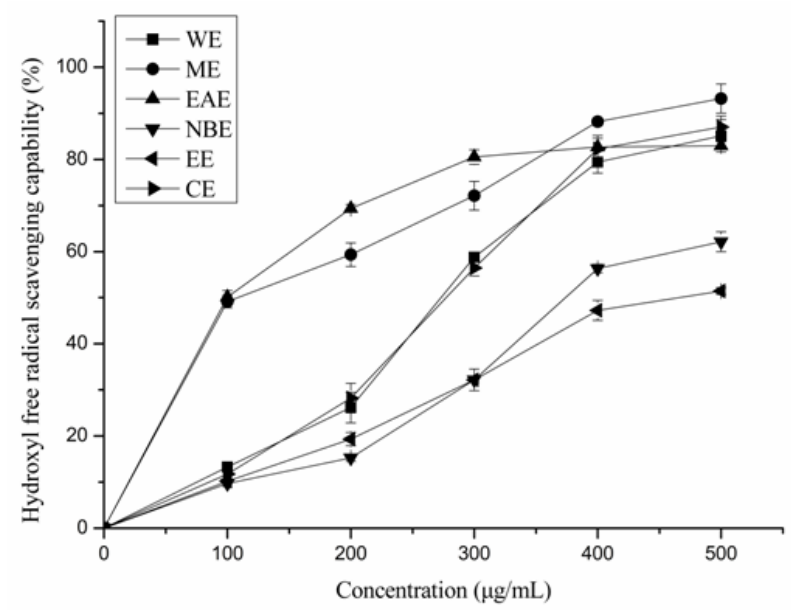

Figure 2. Scavenging activity on hydroxyl free radicals (\%) of the extracts obtained with water extract (WE), methanol extract (ME), ethanol extract (EE), chloroform extract (CE), N-butanol extract (NBE) and ethyl acetate extract (EAE)

\subsubsection{Superoxide Anion Radicals Scavenging Activity}

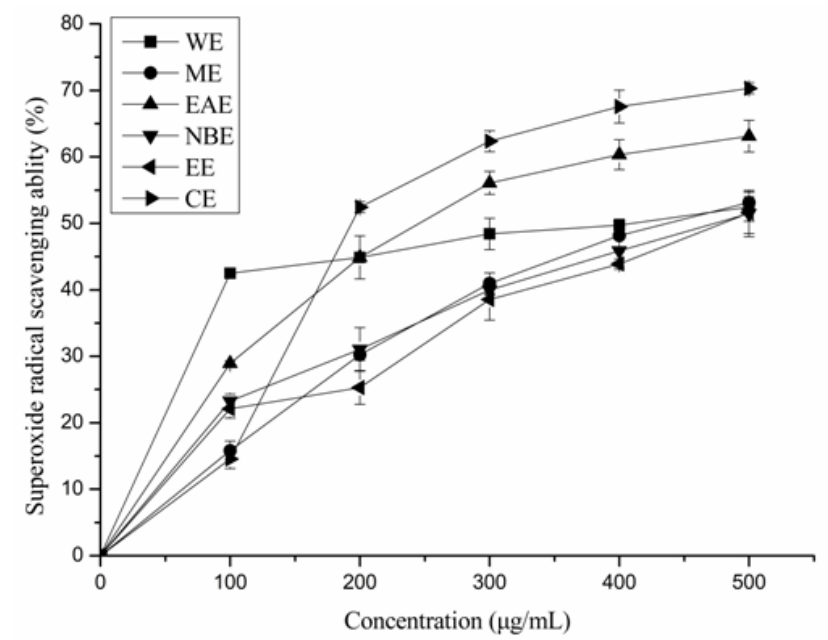

Figure 3. Scavenging activity on superoxide anion radicals (\%) of the extracts obtained with water extract (WE), methanol extract (ME), ethanol extract (EE), chloroform extract (CE), N-butanol extract (NBE) and ethyl acetate extract (EAE)

Superoxide anion is an oxygen-centred radical with selective reactivity, and can generate many dangerous species, including singlet oxygen and hydroxyl radicals which can cause damage to biological macromolecules (lipids, proteins and DNA), leading to various diseases [32]. Superoxide anion has been observed to directly initiate lipid peroxidation. It has also been reported that flavonoids can scavenge superoxide anion radical [33]. Pyrogallol can be autooxidized and generated superoxide anion radical and a chromogenic intermediate. The intermediate has a characteristic absorbance at the wavelength of $320 \mathrm{~nm}$. After adding the extracts into the reaction system, the low absorbance indicates high superoxide anion radial scavenging activity. Figure 3 shows the scavenging activity on superoxide anion radicals of the extracts. The $\mathrm{EC}_{50}$ value of WE, ME, EAE, NBE, EE and CE are 173.41, 451.28, 229.45, 413.42, 419.09, $176.35 \mu \mathrm{g} / \mathrm{mL}$. The superoxide anion scavenging rate of WE, ME, EAE, NBE, EE and CE are 52.48\%, $53.16 \%, 63.12 \%, 51.48 \%$ and $70.31 \%$ respectively under 
the concentration of $500 \mu \mathrm{g} / \mathrm{mL}$. The results are quite different with Sahreen's which indicate water extract with very high superoxide anion scavenging [25]. Moreover the superoxide anion scavenging activities are lower than Hu's researches [19].

\subsubsection{Total Antioxidant Activity}

The total antioxidant activity method is based on the reduction of $\mathrm{Mo}(\mathrm{VI})$ to $\mathrm{Mo}(\mathrm{V})$ by the antioxidant compounds, with the formation of a green phosphate complex with a maximal absorption at $695 \mathrm{~nm}$ [34]. Figure 4 shows the total antioxidant activity of the extracts and the ME and EAE have higher total antioxidant activity. The total antioxidant activity of ME is 1.08, 1.67, 2.78, 2.93 and 4.60 times more than those of EAE, CE, EE, NBE and WE. The total antioxidant activities of extracts are much higher than Vitamin C, but slightly lower than rutin [34].

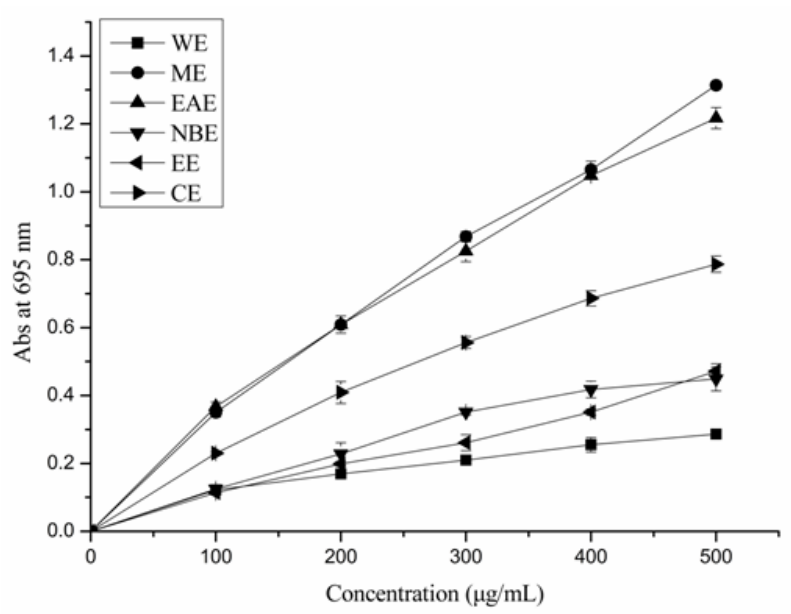

Figure 4. Total antioxidant activity values for the extracts obtained with water extract (WE), methanol extract (ME), ethanol extract (EE), chloroform extract (CE), N-butanol extract (NBE) and ethyl acetate extract (EAE)

\subsubsection{Reducing Power Assay}

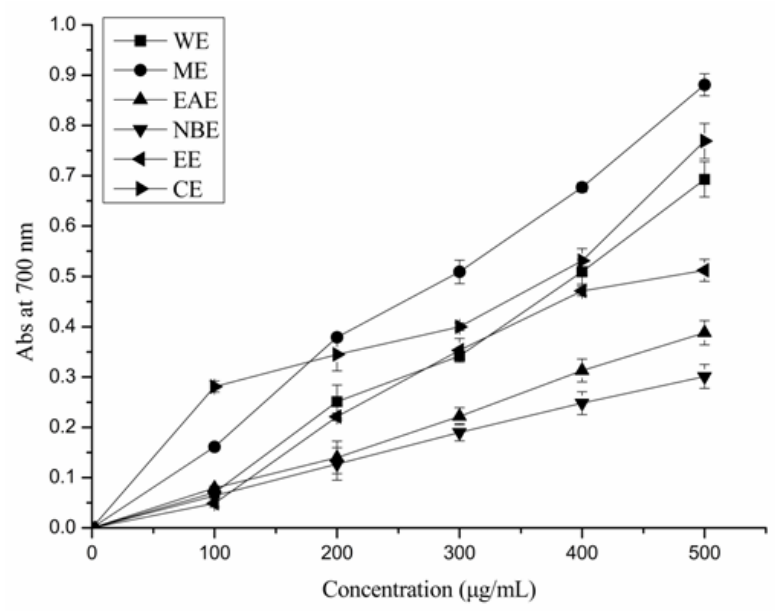

Figure 5. Reducing power values for the extracts obtained with water extract (WE), methanol extract (ME), ethanol extract (EE), chloroform extract (CE), N-butanol extract (NBE) and ethyl acetate extract (EAE)

The reducing power assay is often used to evaluate the ability of an antioxidant to donate electrons [35]. The reducing power assay is based on the reduction of the $\mathrm{Fe}^{3+}$ complex to the $\mathrm{Fe}^{2+}$ in the presence of antioxidants. The $\mathrm{Fe}^{2+}$ concentration can be monitored by measuring the absorbance at 700nm. From Figure 5, the reducing power was positively correlated with the concentrations of the extracts. The reducing power of $\mathrm{ME}$ is $1.15,1.27,1.72$, 2.27 and 2.93 times more than those of CE, WE, EE, EAE and NBE under the concentration of $500 \mu \mathrm{g} / \mathrm{mL}$. The reducing powers of extracts are lower than rutin under the concentration of $500 \mu \mathrm{g} / \mathrm{mL}$ [21].

\section{Conclusions}

The antioxidant properties of extracts with different solvents (water, chloroform, methanol, ethanol, ethyl acetate and N-butanol) from walnut shell were demonstrated. The highest extraction yield was obtained with N-butanol and the extracts showed higher DPPH scavenging activity. The highest total flavonoids content was obtained with ethyl acetate and the extracts had the highest DPPH scavenging activity. However the reducing power of EAE is very low. The highest ability to scavenging hydroxyl free radicals and superoxide anion radicals is $\mathrm{ME}$ and $\mathrm{CE}$. The methanol extract shows the greatest total antioxidant activity and reducing power. The result obtained demonstrated the potential of walnut shell as a source of antioxidant. Nevertheless, there is no a clear correlations about the flavonoids content of extracts and antioxidant ability. This is mainly due to the extracts may be complex mixtures with other antioxidant ingredients. For further research, the factors of temperature, time, solid-liquid ratio, the extract method should to be considered and the ingredients of extracts ought to be identified.

\section{Acknowledgments}

We gratefully acknowledged financial support of the National Natural Science Foundation of China (Grant No. 21466037), Supporting Plan Issue of the Ministry of Science and Technology (2011BAD46B00) and the science and technology major program of Yunnan education bureau (ZD2014009).

\section{References}

[1] Srinivasan A, Viraraghavan T. Removal of oil by walnut shell media. Bioresource Technology, 2008, 99: 8217-8220.

[2] Zabihi M, Haghighi Asl A, Ahmadpour A. Studies on adsorption of mercury from aqueous solution on activated carbons prepared from walnut shell. Journal of Hazardous Materials, 2010, 174: 251-256.

[3] Akbari V, Jamei R, Heidari R, et al. Antiradical activity of different parts of Walnut (Juglans regia L.) fruit as a function of genotype. Food Chemistry, 2012, 135(4): 2404-2410.

[4] Sultana B, Anwar F, Ashraf M. Effect of extraction solvent/technique on the antioxidant activity of selected medicinal plant extracts. Molecules, 2009, 14: 2167-2180.

[5] Belmekki N, Bendimerad N. Antioxidant activity and phenolic content in methanol crude extracts from three Lamiaceae grown in southwestern Algeria. Carcinogenesis, 2012, 4: 6.

[6] Akkol E K, Orhan I E, Yeşilada E. Anticholinesterase and antioxidant effects of the ethanol extract, ethanol fractions and isolated flavonoids from Cistus laurifolius L. leaves. Food Chemistry, 2012, 131: 626-631. 
[7] Fernández-Agulló A, Pereira E, Freire M S, et al. Influence of solvent on the antioxidant and antimicrobial properties of walnut (Juglans regia L.) green husk extracts. Industrial Crops and Products, 2013, 42: 126-132.

[8] Zakaria Z A, Mohamed A M, Jamil N S M, et al. In vitro cytotoxic and antioxidant properties of the aqueous, chloroform and methanol extracts of Dicranopteris linearis leaves. African journal of Biotechnology, 2011, 10: 273-282.

[9] Lateef M, Iqbal L, Fatima N, et al. Evaluation of antioxidant and urease inhibition activities of roots of Glycyrrhiza glabra. Pakistan Journal of Pharmaceutical Sciences, 2012, 25: 99-102.

[10] Kurian G A, Suryanarayanan S, Raman A, et al. Antioxidant effects of ethyl acetate extract of Desmodium gangeticum root on myocardial ischemia reperfusion injury in rat hearts. Chinese Medicine, 2010, 5: 1-7.

[11] Oliveira I, Sousa A, Ferreira I C F R, et al. Total phenols, antioxidant potential and antimicrobial activity of walnut (Juglans regia L.) green husks. Food and Chemical Toxicology, 2008, 46: 2326-2331.

[12] Masuoka N, Matsuda M, Kubo I. Characterisation of the antioxidant activity of flavonoids. Food Chemistry, 2012, 131: 541-545.

[13] Cushnie T P, Lamb A J. Recent advances in understanding the antibacterial properties of flavonoids. International Journal of Antimicrobial Agents, 2011, 38: 99-107.

[14] Fu Y, Chen J, Li Y J, et al. Antioxidant and anti-inflammatory activities of six flavonoids separated from licorice. Food Chemistry, 2013, 141: 1063-1071.

[15] Cao J, Xia X, Chen X, et al. Characterization of flavonoids from Dryopteris erythrosora and evaluation of their antioxidant, anticancer and acetylcholinesterase inhibition activities. Food and Chemical Toxicology, 2013, 51: 242-250.

[16] Li X, Chen W, Chen D. Protective effect against hydroxyl-induced DNA damage and antioxidant activity of Radix Glycyrrhizae (Liquorice Root). Advanced Pharmaceutical Bulletin, 2013, 3: 167-173

[17] Islam F, Quadery T M, Chowdhury S R, et al. Antioxidant and Cytotoxic Activities of Mussaenda macrophylla. Bangladesh Pharm, 2012, 15: 69-71.

[18] Chen N, Yang H, Sun Y, et al. Purification and identification of antioxidant peptides from walnut (Juglans regia L.) protein hydrolysates. Peptides, 2012, 38: 344-349.

[19] Hu T, Liu D, Chen Y, et al. Antioxidant activity of sulfated polysaccharide fractions extracted from Undaria pinnitafida in vitro. International journal of biological macromolecules, 2010, 46: 193-198.

[20] Chaouche T M, Haddouchi F, Ksouri R, et al. Antioxidant activity profiling by spectrophotometric methods of phenolic extract of Prasium majus L. Free Radicals and Antioxidants, 2013, 3: 43-46.

[21] Lue B M, Nielsen N S, Jacobsen C, et al. Antioxidant properties of modified rutin esters by DPPH, reducing power, iron chelation and human low density lipoprotein assays. Food Chemistry, 2010, 123: 221-230.

[22] Alothman M, Bhat R, Karim A A. Antioxidant capacity and phenolic content of selected tropical fruits from Malaysia, extracted with different solvents. Food Chemistry, 2009, 115: 785788.

[23] Sahreen S, Khan M R, Khan R A. Evaluation of antioxidant activities of various solvent extracts of Carissa opaca fruits. Food chemistry, 2010, 122: 1205-1211.

[24] Sajid Z I, Anwar F, Shabir G, et al. Antioxidant, antimicrobial properties and phenolics of different solvent extracts from bark, leaves and seeds of Pongamia pinnata (L.) Pierre. Molecules, 2012, 17: 3917-3932.

[25] Sahreen S, Khan M R, Khan R A. Evaluation of antioxidant activities of various solvent extracts of Carissa opaca fruits. Food chemistry, 2010, 122: 1205-1211.

[26] Chaleshtori R S, Chaleshtori F S, Rafieian M. Biological characterization of Iranian walnut (Juglans regia) leaves. Turkish Journal of Biology, 2011, 35: 635-639.

[27] Valko M, Leibfritz D, Moncol J, et al. Free radicals and antioxidants in normal physiological functions and human disease. The International Journal of Biochemistry \& Cell Biology, 2007, 39: 44-84.

[28] Wei Q, Ma X, Zhao Z, et al. Antioxidant activities and chemical profiles of pyroligneous acids from walnut shell. Journal of analytical and applied pyrolysis, 2010, 88: 149-154.

[29] Lee J, Koo N, Min D B. Reactive oxygen species, aging, and antioxidative nutraceuticals. Comprehensive Reviews in Food Science and Food Safety, 2004, 3(1): 21-33.

[30] $\mathrm{Li} \mathrm{Y}$, Jiang $\mathrm{B}$, Zhang $\mathrm{T}$, et al. Antioxidant and free radicalscavenging activities of chickpea protein hydrolysate (CPH). Food Chemistry, 2008, 106: 444-450.

[31] Loganayaki N, Siddhuraju P, Manian S. Antioxidant activity and free radical scavenging capacity of phenolic extracts from Helicteres isora L. and Ceiba pentandra L. Journal of Food Science and Technology, 2013, 50: 687-695.

[32] Ak T, Gülçin İ. Antioxidant and radical scavenging properties of curcumin. Chemico-Biological Interactions, 2008, 174: 27-37.

[33] Yen G C, Duh P D. Scavenging effect of methanolic extracts of peanut hulls on free-radical and active-oxygen species. Journal of Agricultural and Food Chemistry, 1994, 42: 629-632.

[34] Habib H M, Ibrahim W H, Schneider-Stock R, et al. Camel milk lactoferrin reduces the proliferation of colorectal cancer cells and exerts antioxidant and DNA damage inhibitory activities. Food Chemistry, 2013, 141: 148-152.

[35] Ren J, Zhao M, Shi J, et al. Purification and identification of antioxidant peptides from grass carp muscle hydrolysates by consecutive chromatography and electrospray ionization-mass spectrometry. Food Chemistry, 2008, 108: 727-736. 